\section{俩 Heighten Science \\ P U B L I C A T I O N S Corporation ISSN \\ 2576-9537}

*Address for Correspondence: Dr. Mushtaq Chalkoo, Assistant Professor, Govt. Medical College, Srinagar, Kashmir, India, Email: Mushtaq_chalkoo@rediffmail.com

Submitted: 10 December 2016 Approved: 26 December 2016 Published: 02 January 2017

Copyright: @ 2017 Chalkoo M, et al. This is an open access article distributed under the Creative Commons Attribution License, which permits unrestricted use, distribution, and reproduction in any medium, provided the original work is properly cited.

Keywords: Adrenal glands; Laparoscopy; Techniques

\title{
Laparoscopic Adrenalectomy; A Short Summary with Review of Literature
}

\author{
Mushtaq Chalkoo*, Naseer Awan, Hilal Makhdoomi, Syed \\ Shakeeb Arsalan and Waseem Raja \\ Govt. Medical College, Srinagar, Kashmir, India
}

\section{ABSTRACT}

We present a review article on adrenal glands, with a special reference to their anatomy, physiology, evaluation, laparoscopic operative techniques with a short summary of review of literature.

\section{INTRODUCTION}

The adrenal glands were first described by the Italian anatomist Bartolommeo Eustachi in 1563. The adrenal glands are mustard coloured structures positioned superior and slightly medial to the kidneys in the retroperitoneal space, flattened and roughly pyramidal or crescent shaped weighing $4 \mathrm{Gms}$ each. They are among the highly perfused organs of the body. The right adrenal gland abuts the postero- lateral surface of the hepatic vene cava bounded by the right kidney infero-laterally, diaphragm posteriorly and bare area of the liver anterosuperiorly. The left adrenal lies between left kidney and aorta with inferior limb extending farther caudad towards renal hilum [1].

The German comparative anatomist Albert Von Kolliker is credited with first identifying two distinct portions of the adrenal gland, the cortex and the medulla. Each adrenal gland is composed of 2 distinct parts: the adrenal cortex and the adrenal medulla. The cortex is divided into 3 zones. From exterior to interior, these are the zona glomerulosa, the zona fasciculata, and the zona reticularis.

Edward Kendall, Tadeus Reichitein and Philpi Hench jointly received the 1950 Nobel Prize in Physiology and Medicine for their groundbreaking work on adrenocortical hormones. The adrenal cortex secretes 3 types of hormones: (1) mineralocorticoids (the most important of which is aldosterone), which are secreted by the zona glomerulosa; (2) glucocorticoids (predominantly cortisol), which are secreted by the zona fasciculata and, to a lesser extent, the zona reticularis; and (3) adrenal androgen (mainly dehydroepiandrosterone [DHEA]), which is predominantly secreted by the zona reticularis, with small quantities released from the zona fasciculate. The adrenal medulla is a completely different entity secreting epinephrine (80\%) and norepinephrine $(20 \%)$, with minimal amounts of dopamine. These hormones are responsible for an increase in cardiac output and vascular resistance and for all the physiologic characteristics of the stress response.

Tumors of the adrenal Gland are divided into those arising from the cortex and those from the medulla. The tumors may further be subdivided into" benign" and 
"malignant" or as functioning versus non-functioning tumors. Adrenals are also a good sanctuary for secondary deposits from many organs [2]. Cortical adrenal tumors can be adenomas (cortisol, aldosterone or non-steroid producing), carcinomas (steroid or non-steroid producing) or hyperplasia (primary or secondary due to increased ACTH). Adrenal medullary tumors can be adenomas (pheochromocytoma, neuroblastoma, or ganglionueroma) or carcinoma. Metastatic tumors in adrenal glands can come from lung, breast, lymphoma etc. Miscellaneous adrenal tumors include myelolipoma, haemartoma, black adenoma, haemangioma, teratoma and cystic disease (hydatid and pseudocyst) [3].

Adrenal tumors have been found in $8.7 \%$ of autopsy series with adrenal incidentalomas being reported in $4 \%-7 \%$ of patients undergoing abdominal imaging studies. Adrenal pathology that requires surgical resection spans a large spectrum of diseases. The incidence of adrenal incidentaloma, a term coined in reference to the phenomenon of detecting an otherwise unsuspected adrenal mass on radiologic imaging, has been increasing [4]. The definition of incidentaloma excludes patients undergoing imaging procedures as part of staging and work-up for cancer. During the evaluation of an adrenal mass, 3 questions need to be addressed: (1) Is the tumor hormonally active? (2) Does it have radiologic characteristics suggestive of a malignant lesion? and (3) Does the patient have a history of a previous malignant lesion? The patient should be tested for evidence of hypercortisolism, aldosteronism (if hypertensive), and the presence of a pheochromocytoma. Before consideration of surgical resection, a high degree of certainty of the diagnosis is critical thus, patients with an adrenal incidentaloma should undergo evaluation clinically, biochemically, and radiographically for signs and symptoms of hypercortisolism, aldosteronism (if hypertensive), the presence of a pheochromocytoma, or a malignant tumor [5].

The treatment of adrenal masses is mainly surgical. Earlier mode of surgical treatment was open adrenalectomy requiring extensive transperitoneal exposure. Laparoscopic adrenalectomy, first described by Gagner [6] in 1992, has grown within a few years into an established procedure for surgical removal of adrenal glands. Since the first description of a laparoscopic adrenalectomy by Michel Gagner in 1992, laparoscopic adrenalectomy has quickly become the standard of care for removing the majority of adrenal masses. Multiple prospective and retrospective studies have demonstrated minimal morbidity, short convalescence, and excellent cosmesis with laparoscopic adrenalectomy. These results apply to functional and non-functional tumors. Recently, similar outcomes have been published for the pediatric and nonadrenal cancer patient populations. Most patients spend 1-2 nights in the hospital, with a few centers performing outpatient adrenalectomy in appropriately selected patients. However, as with many technologically advanced procedures, high volume surgeons continue to have the best outcomes [4].

\section{Adrenalectomy techniques}

- Several different techniques have been proposed and are currently being used for the resection of adrenal tumors.

- Lateral transabdominal adrenalectomy (LTA)

- Posterior retroperitoneoscopic adrenalectomy (PRA)

- Anterior transabdominal adrenalectomy (ATA)

- Lateral retroperitoneoscopic adrenalectomy (LPA)

- $\quad$ Robotic adrenalectomy (RA)

- Single port adrenalectomy

- Partial adrenalectomy 


\section{INCLUSION CRITERIA}

The ideal patients for laparoscopic adrenalectomy are the ones mentioned below.

1) Age $>18$ years.

2) Both functional and non-functional adrenal tumors.

3) Size $<6 \mathrm{~cm}$.

4) BILATERAL ADRENAL TUMOURS

\section{EXCLUSION CRITERIA}

1. Contraindications to general anaesthesia e.g. congestive heart failure, chornic renal failure, chronic obstructive lung disease, uncorrectable coagulopathy.

2. General contraindications to laparoscopic surgery.

3. Tumour size $>6 \mathrm{~cm}$.

4. Locally advanced or widely metastatic disease or any other disease having a bearing on the outcome of laparoscopic adrenalectomy in the prospective part should be excluded from the study.

\section{METHODOLOGY}

The patients are initially evaluated in OPD and then admitted for surgery. On admission a detailed history is taken from the patient including the presenting complaints, duration of complaints, past history especially with reference to previous surgery and any other associated conditions such as chronic ailment and any drug intake. General physical examination is done followed by systemic examination and a thorough abdominal and rectal examination.

Each patient is fully investigated to confirm the diagnosis and to rule out associated syndromes. Each patient and his attendants is fully explained about the nature of the procedure in the language which they understand and a written consent is taken from the patient before surgery. Patient should also be informed about the possible complications of the procedure.

The patient's age, sex, and other demographic features, anthropometry, underlying comorbid conditions, and relevant family history is be recorded.Clinical data and parameters like systolic/diastolic BP, heart rate, body temperature, and respiratory rate are noted. The presenting clinical features of the adrenal tumor and any treatment received for it prior to hospitalization should be recorded.

A complete blood count, microscopic examination of urine, blood chemistry including liver and kidney function tests, albumin, calcium, lactate dehydrogenase and random \&/or fasting plasma glucose levels, chest radiograph, and 12 lead electrocardiogram should be obtained in all patients at admission and at subsequent times as required.

All patients need to be evaluated by physician and endocrinologist preoperatively for workup. Endocrine workup should depend on the type of adrenal tumor suspected and should be done as per standard practice. The screening protocol in suspected pheochromocytoma will include measurement of urinary catecholamines metabolites (VMA).

The workup for adrenal cortical tumors will include dexamethasone suppression 
tests (DST), while for suspected aldodsteronoma, a plasma-renin ration should be done. Patients with elevated catecholamine levels or a history of a prior radiographic abnormality in the adrenals should further be evaluated by imaging with CT or MRI. Patients who have elevated urinary VMAlevels and a grossly visible pheochromocytoma on radiographic imaging are recommended for adrenalectomy.

Preparation for surgery pharmacologically is established by administration of $\alpha$-receptor blockade. Beta-blockade will be added only after adequate $\alpha$-receptor blockade. For patients with a unilateral tumor and no grossly visible disease in the contralateral adrenal, a unilateral approach to adrenalectomy will be undertaken. Laparoscopic adrenalectomy be carried out using a transabdominal lateral approach preferably.

\section{TECHNIQUE}

\section{Transperitoneal surgical approach}

Trans peritoneal approach offers the greatest visualization of the operative field, reducing intraoperative injuries and ensuring minimal morbidity.

\section{Left adrenalectomy}

We generally use three 5-mm working ports and one $10-\mathrm{mm}$ camera port for leftsided procedures.The first $10-\mathrm{mm}$ port is inserted in the umbilicus or at the lateral border of the rectus abdominal muscle just above the level of the umbilicus for the camera. Two subcostal 5-mm ports placed one in the midclavicular line and the other in the lateral border of the rectus abdominal muscle. The third 5-mm subcostal trocar is inserted in the anterior axillary line.

The initiation of the left adrenalectomy requires incising along the white line of Toldt from the splenic flexure to the sigmoid junction to allow mobilization of the left colon. The descending colon is reflected medially and subsequent division of the phrenocolic and splenorenal ligaments allows the colon to fall away out of the visual field. Dissection is carried out between the Gerota's fascia and the mesocolon. Dissection in this plane will facilitate access to the renal and adrenal vein. The retractor is used to retract the kidney laterally, correct identification of the vasculature must be confirmed prior to isolation and clipping of the adrenal vein. The inferior dissection is performed after the adrenal vein has been controlled. Bipolar diathermy is adequate to control the left adrenal vein before it is divided by endoshears or the ultrasonic shears. Dissection is carried out just superior to the renal vein until the post abdominal wall is identified. Hilar lymphatics of the kidney are avoided unless adrenocortical carcinoma is suspected. Care is taken not to injure branches of the renal artery. Attempts are made to leave periadrenal fat surrounding the gland, to ensure a complete and wide excision of the adrenal gland. This technique allows the surgeon to manipulate the tissue without directly grasping the adrenal, avoiding annoying bleeding. Once the inferior dissection is complete the medial dissection is carried out from the renal vein in a cephalad direction. The medial border for this dissection is the crus of the diaphragm overlying the suprarenal aorta. The lateral dissection is in a plane extending between the renal cortex and the perinephric fat adjacent to the adrenal gland.

This region is usually avascular, but care must be taken to avoid upper pole renal vessels. The superior dissection is the last step before the adrenal gland is free within the abdomen along with periadrenal fat. The left inferior phrenic vein is generally present during the superior dissection and must be carefully identified and divided to avoid troublesome bleeding. The dissected gland is placed in an Endopouch that is inserted through the camera port.

\section{Right adrenalectomy}

Five ports are used for right-sided procedures. The trocars are placed in a mirror 
image to the left side with the addition of a $5 \mathrm{~mm}$ in the epigastrium for liver retraction. The epigastric trocar is inserted just to the left of the midline in relation to the lower edge of the liver, so that it does not interfere with the right-handed instrument and trocar. The first step is division of the triangular ligament and careful cephalad retraction of the liver using a locking grasper that is inserted through the epigastric trocar Figure 1. The grasper holds a fold of the peritoneum or the diaphragm on the lateral abdominal wall, and retracts the liver.

Unlike the left side, the colon rarely requires significant mobilization. At this point, the subhepatic inferior vena cava (IVC) should be identified, lateral and posterior to the gall bladder. This phase can be difficult in obese patients or those with Cushing's syndrome where excess adipose tissue is present.

The peritoneum along the lateral aspect of the IVC is incised to expose the IVC just below its intrahepatic course. The duodenum often needs to be mobilized to expose the IVC.

Dissection is next carried inferiorly by incising the peritoneum along the lateral edge of the vena cava to the superior edge of the renal vein. Further dissection extends posteriorly, bordering the superior aspect of the renal vein, for the inferior adrenal dissection (Figure 2). The posterior abdominal wall is encountered, ensuring that the renal artery or its branches are safeguarded.

The inferior adrenal gland and periadrenal tissue is retracted laterally with the PEER retractor, as the medial dissection is performed in a cephalad direction (Figure 3). The dissection proceeds superiorly just lateral to the cava until the short right
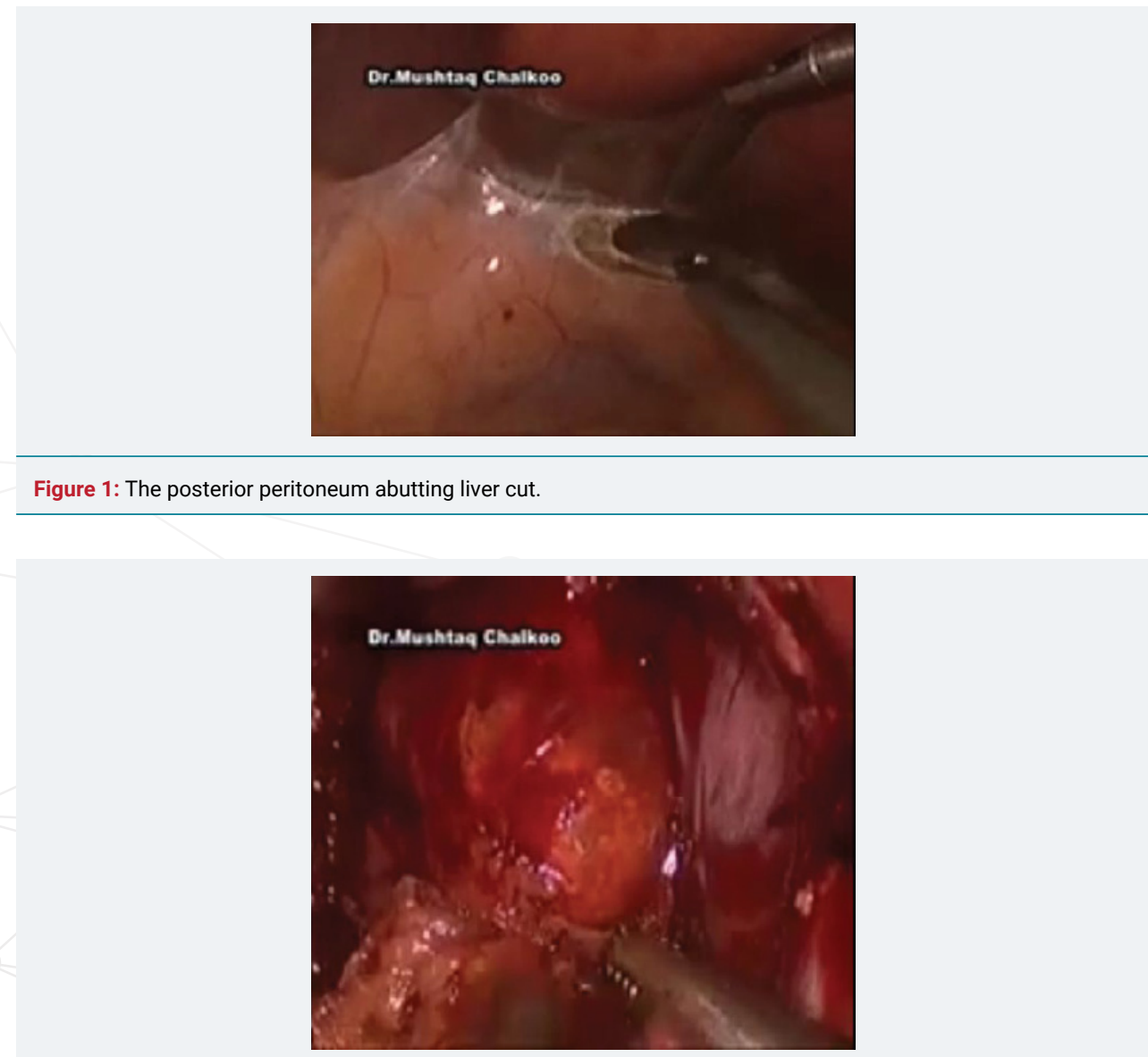

Figure 2: The lateral,inferior dissection done. 
adrenal vein is identified its divided. Dissection of the gland is subsequently carried out with care taken at the medial aspect where the wall of the IVC closely approximates the adrenal. The adrenal may extend posterior to the cava and this dissection is completed by following the wall of the cava and gentle medial retraction of the IVC. Once the medial dissection is completed, the lateral dissection is performed just as described for the left adrenalectomy. Once complete mobilization is accomplished and hemostasis is achieved, the specimen is removed with the EndoPouch (Figures 4,5 and 6).
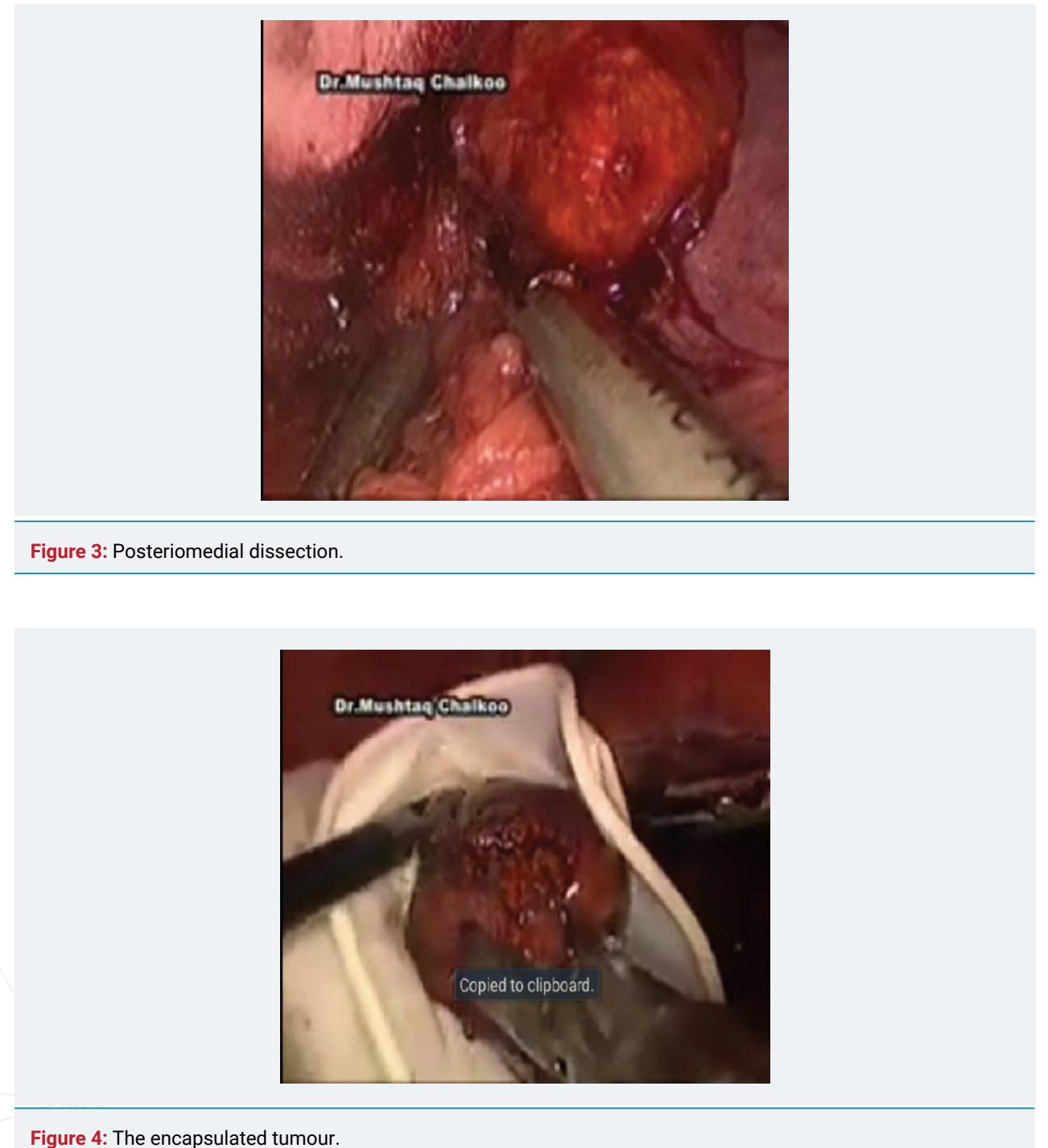

Figure 4: The encapsulated tumour.

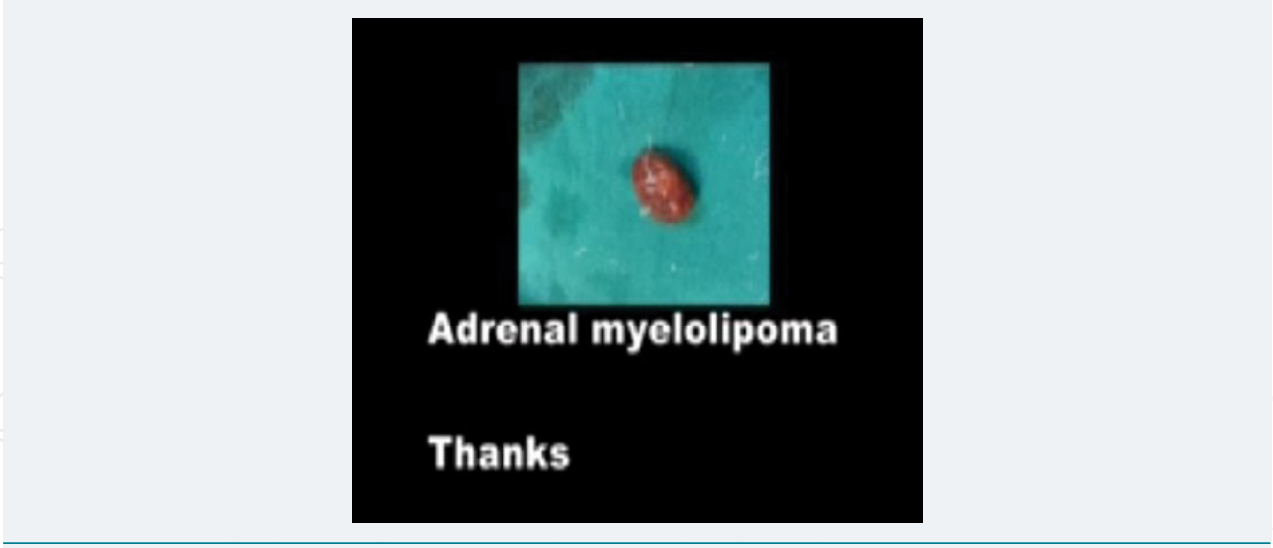

Figure 5: The adrenal myelolipoma. 


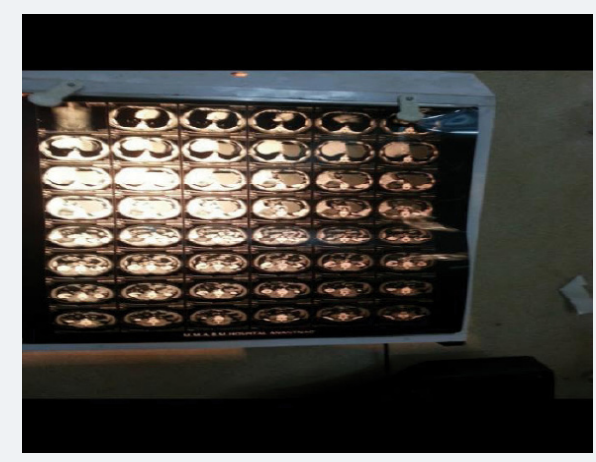

Figure 6: The CT scan showing right adrenal mass.

\section{RESULTS}

The results of our early experience with laparoscopic Adrenalectomy were quite encouraging with minimal blood Loss, around 70 minutes operation time and no conversion. The average hospital stay was 3 to 6 days.

\section{REVIEW OF LITERATURE}

The earliest anatomical description of the adrenals in the mid sixteenth century (1563) treastse "Opuscula Anatomica" by Bartholomacus Eustachius was largely ignored until almost 200 years later when Pope Clement discovered a large collection of anatomical plates attributed to Eustachius in the library of the Vatican City [7]. The un ending research endeavours of numerous scholars and scientists have unveiled the various aspects of this important endocrine gland especially in the later half of the $20^{\text {th }}$ century. Approximately one half of clinically detected adrenocortical neoplasms are benign and functioning. Most are solid and present with signs and symptoms of glucocorticoid (Cushing's Syndrome) or mineralocorticoid (Conn's syndrome) excess. The other half of solid neoplasms are primary adrenocortical carcinoma, about half of which are functioning. Non-functioning adrenocortical tumors may be cysts, adenomas, or other rare benign tumors such as myelolipomas. Occasionally they are carcinomas [8]. As use of cross-sectional imaging continues to rise, adrenal masses are frequently detected incidentally in the daily practice of radiology.

As use of cross-sectional imaging continues to rise, adrenal masses are frequently detected incidentally in the daily practice of radiology. These adrenal masses, commonly referred to as adrenal incidentalomas, are asymptomatic masses, $1 \mathrm{~cm}$ or more discovered on imaging studies performed for reasons unrelated to adrenal disease. The prevalence of incidental adrenal mass at CT is approximately 4\% to 5\%, reflecting the estimated prevalence in the general population of 3\% to 7\% [4]. Adrenal masses are common in general population, with a mean prevalence determined from several large autopsy studies of $2.3 \%$. Most of these incidentally found masses are benign, with adenomas the most common pathology. The large majority of incidentalomas are nonfunctioning cortical adenomas and $6 \%$ are functioning autonomous cortisol-secreting (5\%) and sex hormone aldosterone-producing (1\%). Malignant incidentalomas account for approximately $2 \%$ to $3 \%$ of all detected lesions, increasing in number and proportion with patients age [9].

Brunt et al. [10] Studied the records of 66 consecutive patients with benign adrenal neoplasms who underwent adrenalectomy from 1988 through 1995 were retrospectively reviewed. Patients were divided into three groups based on the operative approach: group I $(n=25)$, open anterior transabdominal approach; group II $(n=17)$, open posterior retroperitoneal approach; and group III $(n=24)$, laparoscopic transabdominal flank approach.He observed that the three groups were similar in 
age, gender, American Society of Anesthesiologists class, and distribution of unilateral compared with bilateral adrenalectomy. Mean tumor size was slightly larger in group I $(3.4+/-1.4 \mathrm{~cm})$ than in group II $(2.4+/-1.4 \mathrm{~cm})$ or group III $(2.7+/-1.4 \mathrm{~cm})(\mathrm{p}=$ NS). Mean operative times for unilateral adrenalectomy were $142+/-38$ minutes in group I, $136+/-34$ minutes in group II, and $183+/-35$ minutes in group III $(\mathrm{p}<0.001$, groups I and II compared with group III). For bilateral adrenalectomy, mean operative times were $205+/-71$ minutes (group I), $328+/-11$ minutes (group II), and $422+/$ 77 minutes (group III). Patients who underwent laparoscopic adrenalectomy had significantly less operative blood loss (mean, $104 \mathrm{~mL}$ compared to $408 \mathrm{~mL}$ in group I and $366 \mathrm{~mL}$ in group II, $\mathrm{p}<0.001$ ) and a lower incidence of perioperative blood transfusion. Laparoscopic adrenalectomy was also associated with significantly reduced parenteral pain medication requirements $(\mathrm{p}<\mathrm{or}=0.001)$ and more rapid resumption of a regular diet $(\mathrm{p}<$ or $=0.01$ ) compared to open adrenalectomy. Postoperative length of stay was significantly longer in group I ( $8.7+/-4.5$ days) and in group II $(6.2+/-3.9$ days $)$ after open adrenalectomy than after laparoscopic adrenalectomy (3.2+/- 0.9 days) (p $<0.01$ ). Total hospital charges were similar for groups II and III but somewhat higher for group I. Patients were able to resume 100 percent activity an average of $10.6+/$ 4.9 days after laparoscopic adrenalectomy and returned to work a mean of $16.0+/-6.1$ days postoperatively [10].

Gagner et al. [11] reviewed one hundred consecutive laparoscopic adrenal procedures from January 1992 until November 1996 were eighty-eight patients underwent 97 adrenalectomies and biopsies. The mean age was 46 years (range, 1784 years). Indications were pheochromocytomas $(n=25)$, aldosterone producing adenomas $(\mathrm{n}=21)$, nonfunctional adenomas $(\mathrm{n}=20)$, cortisol-producing adenomas $(\mathrm{n}=13)$, Cushing's disease $(\mathrm{n}=8)$, and others $(\mathrm{n}=13)$. Fifty-five patients had previous abdominal surgery. Mean operative time was 123 minutes (range, 80-360 minutes), and estimated blood loss was $70 \mathrm{~mL}$ (range, 20-1300 mL). There was no mortality, and morbidity was encountered in $12 \%$ of patients, including three patients in whom venous thrombosis developed with two sustaining pulmonary emboli. During pheochromocytoma removal, hypertension occurred in $56 \%$ of patients and hypotension in $52 \%$. There were three conversions to open surgery. The average length of stay has decreased from 3 days (range, 2-19 days) in the first 3 years to 2.4 days (range, 1-6 days) over the past 16 months. During follow-up (range, 1-44 months), two patients had renovascular hypertension and none had recurrence of hormonal excess [11].

Wu et al. [12] did a comparative study of Laparoscopic (LA) and Open Adrenalectomy (OA) for a total of 67 patients. Thirty patients underwent $\mathrm{OA}$ and 37 patients received LA. The introperative and the perioperative data analysis was focused on surgery time, blood loss, pain scale rating, resumption of oral feeding, hospital stay, complications and convalescence. LA was completed in all 37 patients without conversion to OA without mortality. Surgery time did not differ in the two groups. There was less blood loss in LA group ( $\mathrm{p}=0.021$ ).the postoperative pain scale rating was lower in LA group $(\mathrm{p}=0.035)$ as was analgesia demand $(\mathrm{p}<0.001)$.Oral feeding was resumed earlier in LA group $(\mathrm{p}<0.001)$ and had shorter postoperative hospital stay $(\mathrm{p}<0.001)$. Complication rate was similar in both groups. In the LA group, patients with primary aldosteronism had shorter surgery time and less blood loss than patients with other tumor types $(\mathrm{p}<0.05)[12]$.

Bhargav et al. [13] from India studied 59 cases of incidentalomas retrospectively (1991to 2005. Mean age of the patients was $46+/-12$ years (M: $F=1: 1.1$ ). The incidentaloma measured more than $3 \mathrm{~cm}$ in $91 \%$ of cases and more than $6 \mathrm{~cm}$ in $70 \%$ of cases. The clinical scenarios leading to detection of incidentaloma included abdominal (56.6\%), genitourinary (24.5\%), and systemic complaints $(15.1 \%)$ and routine medical checkup (3.7\%). Most of cases were found by ultrasonography $(\mathrm{n}=$ 
41), and remaining by CT scan ( $\mathrm{n}=10)$, and MRI $(\mathrm{n}=2)$. The incidence of functioning tumors was $41.5 \%$ (hypercatecholinism $37.7 \%$ and hypercortisolism 1.9\%). Fortynine patients were operated on. The important final pathology included ACC (7.5\%), pheochromocytoma (PCC) (43\%), adrenal cysts (13.2\%), myelolipoma (11.3\%), and inflammatory lesions (9.4\%). They concluded that Adrenalectomy is a justified procedure for large incidentalomas, although the concern may not always be an underlying malignancy [13].

The management of adrenal masses is mainly surgical. Initial mode of surgical treatment was open adrenalectomy requiring extensive transperitoneal exposure. Since it was first described by Ganger [9] in 1992, laparoscopic adrenalectomy has grown within a few years into an established procedure for surgical removal of adrenal glands. Adrenalectomy is indicated in most functional adrenal neoplasms and large incidentalomas. Many comparative studies have been done in the past for open versus laproscopic adrenalectomy $[10,12]$.

Simforoosh et al. [14] studied a total of 67 laparoscopic adrenalectomies performed during the 10 years between 1995 and 2005. A transperitoneal lateral approach was used in 65 (97.0\%) of the patients, and retroperitoneal approach was used in 2 (3.0\%). The clinical characteristics and the outcomes were reviewed in a retrospective study. Indications for laparoscopic adrenalectomy were as follows: pheochromocytoma in 28 patients (41.8\%), aldosterone producing adenoma in 15 (22.4\%), pseudocyst in $6(9.0 \%)$, Cushing syndrome (macronodular adrenocortical hyperplasia) in $5(7.5 \%)$, nonfunctioning adenoma (incidentaloma) in 5 (7.5\%), myelolipoma in $2(3.0 \%)$, almost normal adrenal tissue in $2(3.0 \%)$, adrenal cyst in $2(3.0 \%)$, adenocarcinoma in $1(1.4 \%)$, and schwannoma in $1(1.4 \%)$. The mean operative time for unilateral cases was $149.0 \pm 36.1$ minutes. The mean intra operative blood loss was $126 \pm 36$ $\mathrm{ml}$. Conversion rate to open surgery was $7.5 \%$. Reoperation due to hemorrhage was performed in 1 patient [14].

Asari et al. [15] studied the frequency of malignancy, oncologic outcome and perioperative morbidity between small $(\leq 60 \mathrm{~mm})$ and large $(>60 \mathrm{~mm})$ adrenal tumors treated by endoscopic adrenalectomy (EA) in 289 patients with mean follow up of $87.7 \pm 45.1$ months. Patients were divided in those with tumor size $\leq 60 \mathrm{~mm}$ (group $1 ; \mathrm{n}$ $=252$ ) and $>60 \mathrm{~mm}$ (group $2 ; \mathrm{n}=37)$. Patient age $(\mathrm{P}=.43$ ), gender $(\mathrm{P}=.09)$, tumor side $(\mathrm{P}=.17)$, and operative time $(\mathrm{P}=.33)$ showed no difference in both groups. Functioning tumors were observed in $85 \%$ of patients in group 1 compared with $46 \%$ in group 2 $(\mathrm{P}=.0001)$. Seven $(2.8 \%)$ patients in group 1 and $7(18.9 \%)$ in group 2 had malignant tumors $(\mathrm{P}=.0001)$. Neither rate of conversion $(\mathrm{P}=.71)$ and postoperative complication $(\mathrm{P}=.27)$ nor recurrence of malignancy $(\mathrm{P}=.48)$ differed between both groups. Estimated disease-free survival after 5 years in malignant lesions was $87.5 \pm 11.7 \%$ for group 1 and $62.5 \pm 21.3 \%$ for group $2(\mathrm{P}=.49)$.EA is a safe and feasible procedure in the majority of large adrenal tumors. Tumor size does not affect the outcome of surgery. In case of malignancy, it does not increase the rate of local recurrence. In experienced hands, tumor size should not influence the decision of surgical access (endoscopic versusopen) [15].

Hattori et al. [16] studied retrospectively the predictive factors for Perioperative Complications of Laparoscopic Adrenalectomy including single site surgery performed or supervised by experienced laparoscopic surgeons in 265 consecutive unilateral Las. The transabdominal approach was used in 248 patients, while a retroperitoneal approach was used in 17 patients. Laparoendoscopic single-site adrenalectomy was performed in 58patients. There were no postoperative deaths. Atleast one postoperative complication occurred in $12(4.6 \%)$ patients. No patient underwent reoperation for a complication. Only one ( $0.4 \%$ ) patient's procedure was converted to open surgery, and only this patient needed a blood transfusion during the operation. One patient who 
underwent laparoendoscopic single-site adrenalectomy had the procedure converted to conventional laparoscopic adrenalectomy. Multivariable logistic regression analysis showed that an American Society of Anesthesiologists-physical status grade 3 or above was the only predictive factorfor perioperative complications.

\section{CONCLUSION}

American Society of Anesthesiologists-physical status grade 3 or above was a statistically significant factor for perioperative complications associated with laparoscopic adrenalectomy that involved laparoendoscopic single-site adrenalectomy, which was performed or supervised by an experienced laparoscopic surgeon. According to the findings of this retrospective study, single-site operation, obesity, adrenal tumor size, and tumor type may not be considered as risk factors for perioperative complications after LA performed or supervised by an experienced laparoscopic surgeon [16].

Hence on reviewing the literature, LA appears to be the standard minimally invasive surgical procedure for the adrenal masses. However larger tumors may need to be tackled by OA, although there are small case series where giant adrenal masses (without preoperative diagnosis of invasive adrenal carcinoma) have been removed by LA [17].

Al-Otaibi [18] published his 10 year experience of Laproscopic adrenalectomies of 34 patients. All underwent lateral transperitoneal Laparoscopic adrenalectomies. 24 right sided and 10 left sided lesions. All except one had successful LA. Complication occurred in one patient who required open conversion because of bleeding. In addition one patient suffered a pancreatic injury who was managed conservatively. The average operative time was 2 hours and 30 minutes [18].

Kulis et al. [19] published his series of 306 patients using the transperitoneal lateral approach for LA. No major operative complications were noted, and postoperative complications included a pulmonary embolism and two cases of pneumonia. Conversion to the open approach was necessitated in two cases. The median operative time was $95 \pm 29$ minutes (range, 45-145 minutes). Estimated blood loss was $60 \mathrm{~mL}$ (range, 30$150 \mathrm{~mL}$ ). The mean size of the removed gland was $5.9 \pm 1.6 \mathrm{~cm}$ (range, $3-13 \mathrm{~cm}$ ). The mean size of the tumor was $5 \pm 2 \mathrm{~cm}$ (range, $0.5-12 \mathrm{~cm}$ ). The median hospitalization was $4 \pm 3.7$ days (range, 2-22 days). Adrenal pathology included adenoma $(n=164)$, pheochromocytoma $(n=79)$, hyperplasia $(n=35)$, metastatic carcinoma $(n=22)$, cyst $(n=9)$, myelolipoma $(n=9)$, hemangioma $(n=3)$, ganglioneuroma $(n=3)$, and melanoma $(n=2)[19]$.

We conclude from the review of literature that laparoscopic adrenalectomy is a recommended minimal invasive procedure for adrenal masses for tumours lesser then $6 \mathrm{~cm}$ size.however tumours bigger than $6 \mathrm{cms}$ should either be operated by laparoscopic assisted technique or by open method.

\section{REFERENCES}

1. Townsend JCM, Beauchamp RD, Evers BM, Mottox KL, editors. Adrenal Glands, in Sabistan Text Book of Surgery, $19^{\text {th }}$ edn. 2012, Elsevier Saunders, Philadelphia.

2. Bertagna C, Orth DN. Clinical and laboratory findings and results of therapy in 58 patients of adrenocortical tumors admitted to single medical centre (1951-1978). Am J Med. 1981; 71: 855875. Ref.: https://goo.gl/RnZKis

3. Seikavizza JL, Bernadino ME, Samaan NA. Suprarenal mass and its differential diagnosis. Urology. 1981; 18: 625-632. Ref.: https://goo.gl/m2jNyv

4. Stefanidis D, Goldfarb M, Kercher KW, Hope WW, Richardson WSAGES, et al. SAGES Guidelines for the Minimally Invasive Treatment of Adrenal Pathology. Surg Endosc. 2013; 27: 3960-3980. Ref. https://goo.gl/ZZu4u6 
5. Zeiger MA, Thompson GB, Duh QY, Hamrahian AH, Angelos P, et al. The American Association of Clinical Endocrinologists and American Association of Endocrine Surgeons medical guidelines for the management of adrenal incidentalomas. Endocr Pract. 2009; 1: 1-20. Ref.: https://goo.gl//pWyfH

6. Gagner M, Lacroix A, Bolte E. Laproscopic adrenalectomy in Cushings syndrome and Pheochromocytoma. N Engl J Med 1992; 327: 1033. Ref.: https://goo.gl/QrifoT

7. Eustachius B. Opuscula Anatomica.Vince, Vencentos Luchinus, 1563.

8. Norman WT, Polly SYC. Diagnosis and treatment of functioning and non-functioning adrenocortical neoplasms including incidentalomas. Surg Clin North Am 1987; 67: 423-427.

9. Blake MA, Holalkere NS, Boland GW. Imaging techniques for adrenal lesion characterization. Radiol Clin North Am. 2008; 46: 65-78. Ref.: https://goo.gl/bZ8rdK

10. Brunt LM, Doherty GM, Norton JA, Soper NJ, Quasebarth MA, et al. Laproscopic adrenalectomy compared to open adrenalectomy for benign adrenal neoplasms. J Am Coll Surg. 1996; 183: 1-10. Ref.: https://goo.gl/uwgfLG

11. Gagner M, Pomp A, Heniford BT, Pharand D, LacroixA. Laparoscopic adrenalectomy: lessons learned from 100 consecutive procedures. Ann Surg. 1997; 226: 238-246. Ref.: https://goo.gl/m0g03d

12. Wu CT, Chiang YH, Chou CC, Liu KL, Lee SH, et al. Comparative study of Laproscopic and open Adrenalectomy. Chang Gung Med J. 2006; 29: 468-473. Ref.: https://goo.gl/pwJ7HV

13. Bhargav PR, Mishra A, Agarwal G, Agarwal A, Verma AK, et al. Adrenal Incidentalomas: Experience in a developing country. World J Surg. 2008; 32: 1802-1808. Ref.: https://goo.gl/7DZiuF

14. Simforoosh N, Majidpour HS, Basiri A, Ziaee SAM, Behjati S, et al. Laparoscopic Adrenalectomy, Ten year Experience 67 Procedures. Urol J. 2008; 5: 50-54. Ref.: https://goo.gl/gpqdCF

15. Asari R, Koperek O, Niederle B. Endoscopic adrenalectomy in large adrenal tumors. Surgery. 2012; 152: 41-49. Ref.: https://goo.gl/ccW6ei

16. Hattori S, Miyajima A, Maeda T, Hasegawa M, Takeda T, et al. Risk Factors for Perioperative Complications of Laparoscopic Adrenalectomy Including Single-Site Surgery. J Endourol. 2012 26: 1463-1467. Ref.: https://goo.gl/GgvCA8

17. Maestroni U, Ferretti S, Ziglioli F, Campobasso D, Cerasi D, et al. Laparoscopic adrenalectomy in giant masses. Urologia. 2011; 78: 54-58. Ref.: https://goo.gl/6z4YHh

18. Al-Otaibi KM. Laparoscopic adrenalectomy: 10 years experience. Urol Ann. 2012; 4: 94-97. Ref.: https://goo.gl/71KBMy

19. Kulis T, Knezevic N, Pekez M, Kestelan D, Grkovic M, et al. Laparoscopic adrenalectomy: lessons learned from 306 cases. J Laparoendosc Adv Surg Tech A. 2012; 22: 22-26. Ref.: https://goo.gl/ThWBe2 